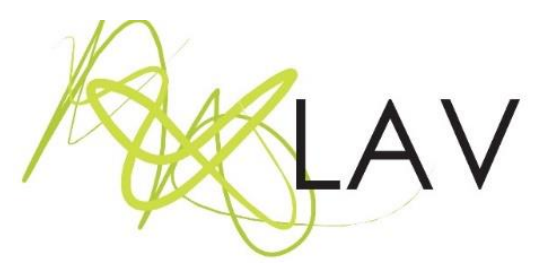

Infâncias, quadrinhos e ruralidade:

\title{
Quatro fragmentos das histórias que vivi para me tornar no que sou
}

\author{
Children, comics and rurality:
}

Four fragments of the stories I've lived to become what I am

Leonardo Charréu

Escola Superior de Educação de Lisboa

\begin{abstract}
Resumo
Este é um artigo escrito na primeira pessoa e adopta uma perspectiva literária, essa mesmo tão defendida por Elliot Eisner, a partir da qual ele, tal como eu, acreditava ser também possível narrar ciência. Por isso, nem Eisner nem Max Van Manen, esse fenomenólogo da educação enquanto experiência vivida, aparecerão a pontuar o meu texto. Mas declaro solenemente que este texto é-lhes devedor da sua substância implícita. Consequentemente, é um texto limpo e vivo, sem vozes de teóricos mortos, que é o mesmo que dizer sem bibliografia. Logo, perigosamente, anti-acadêmico nesse sentido de ter que estar polvilhado de referências, citações e outras meta-narrativas para se considerar "científico". Busca a coerência da originalidade e é precisamente consciente que a vida de cada um é única e irrepetível. E julgo ser na ligação entre estes fragmentos que se encontrará talvez a resposta ao desafio lançado pela Revista: como nos tornamos arte educadores.
\end{abstract}

Palavras-chave: Infância, Escolarização, Ruralidade, Autobiografia

\begin{abstract}
This is an article written in the first person and adopts a literary perspective, that one greatly defended by Elliot Eisner, from which he, like myself, believed it was also possible to narrate science. Therefore, neither Eisner nor Max Van Manen, this phenomenologist of education as a lived experience, will appear to punctuate my text. But I solemnly declare that this text is indebted to them of their implicit substance. Consequently, it is a clean and living text, without voices of the dead theoreticians, which is the same as saying without bibliography. It is, therefore, dangerously anti-academic in the sense of having to be sprinkled with references, citations and other meta-narratives to be considered "scientific." It seeks the coherence of originality and is precisely conscious that each one's life is unique and unrepeatable. And I think that it was linking those fragments that the answer to the thematic challenge launched by this journal could be found: how we become art educators.
\end{abstract}

Keywords: Childhood, Schooling, Rurality, Autobiography 


\section{Fragmento 1: Quadrinhos, o passaporte para o futuro}

A banda desenhada que fazia as delicias da criançada da minha infância é mais conhecida no Brasil como "quadrinhos" e nos países anglo-saxónicos, como "comics" ou "graphic novels". Adoto o termo utilizado no Brasil por manter com ele uma relação de afeto. Quadrinhos é mais ternurento do que banda desenhada e por isso é o termo que preferi usar no texto que doravante se desenvolve. Do mesmo modo, preferi utilizar a grafia da língua portuguesa, escrita e falada na Europa, pré-acordo ortográfico, inclusive, para ser mais fiel e coerente com a época histórica narrada.

Nos finais dos anos sessenta do século passado, no largo passeio, em cimento, do cineteatro Inácio Teixeira Rocha, situado bem no centro da aldeia, era frequente eu esperar, todas as sextas feiras, ao final da tarde, a camioneta da carreira que vinha dos lados de Lisboa. Trazia dois dos meus tios maternos depois de mais uma semana de trabalho na construção civil nas cidades-dormitório que cresciam como cogumelos à volta da grande Lisboa. Não era uma, mas várias camionetas que chegavam cheias de operários, jovens que preferiam o trabalho na construção ao duro trabalho nos campos agrícolas da região. E de repente, num ápice, aquele largo enchia-se de movimento de pessoas, carregando sacos e malas de cartão. Alguns, esperados pelas mães e por outros familiares, depressa tomavam o rumo das suas casas, outros com as namoradas, ao longe, tímidas (agora mais tranquilas) a confirmarem os seus regressos, demoravam-se nas várias tabernas que bordejavam aquele largo, centro vital da aldeia. Punham moedas nas musicbox, uma inovação que tinha chegado à aldeia mais habituada aos sons da concertina e do acordeão. Escolhiam discos românticos em vinil do Roberto Carlos na esperança que a letra comunicasse aos magotes de raparigas namoradeiras que passavam de um lado para o outro, aquilo que não tinham coragem de Ihes dizer: "Eu te amo, Eu te amo...".

Assim que vislumbrava os meus tios, dava um salto de alegria e corria para um abraço deles. Sabia que me traziam, invariavelmente, livros e revistas de quadrinhos com que eu passava boa parte do resto dos dias da semana. Foi com o Tex Tone, o Mascarilha, o Mandrake e o Super-homem, entre muitos outros heróis, que aprendi a ler. Mais aí do que no livro oficial de texto da quarta classe com que o regime fascista português nos atanazava a cabeça. Aquele manual único, de capas cartonadas grossas, com ilustrações de jovens sorridentes e obedientes que apareciam, por vezes, no meio da monotonia do texto, quase sempre com intuito moralista e doutrinário. E aprendi muito depressa a ler assim que ingressei na escola primária, no outono de 1970. 
Rapidamente me pus a imitar os desenhos das minhas revistinhas de quadrinhos, enchendo cadernos pautados e quadriculados, esses mesmos cadernos que deveriam ser para texto e matemática. E quando se acabavam, desenhava em papel almaço de embrulhar bacalhau ou em qualquer pedaço de papel que me viesse parar às mãos.

As imitações, cada vez mais perfeitas, deram lugar também a algumas originalidades quando cheguei à quarta classe. Roberto Ivens, herói explorador das Áfricas, foi a primeira personagem a sair da prática mimética com que ia conquistando, sistematicamente, um numeroso grupo de admiradores entre os meus coleguinhas da escola masculina e, também, da escola feminina que funcionava do outro lado do muro. Uma separação escolar de gênero que nos entristecia a todos, imagem de marca do Estado Novo que, afinal, era mais velho do que nos queria fazer crer.

Enquanto os meus colegas jogavam a bola, corriam e saltavam a corda, ou jogavam ao pião, eu, desenhava. Desenhava compulsivamente, sem parar, e gastava num simples par de semanas, uma caixa inteira de lápis de cor Viarco de fabrico nacional. Gastava tudo, até os lápis, afiados vezes sem conta, com menos de um centímetro de tamanho, já não se segurarem nos meus dedos. Sob os protestos da minha mãe, sempre muito parcimoniosa na gestão do parco orçamento familiar, lá ia comprar, com regularidade, mais uma caixa de lápis de cor. Em regra, com seis cores, que eram bem mais baratas.

Acontecia também, para grande alegria minha, que os meus colegas mais abonados, que eram bem poucos naquele tempo, pediam-me desenhos e forneciam-me o material. Por vezes, traziam-me canetas de feltro e as cores vivas e o cheiro característico a álcool nunca mais saíram das minhas recordações. Desenhava coloridos e vistosos bouquets de flores para as meninas do outro lado do muro e movimentadas histórias de índios e cowboys para a masculinidade troglodita do lado de cá.

\section{Fragmento 2: Eu queria um corpo para a liberdade}

Nessa manhã do longínquo e histórico dia 25 de abril de 1974 esperamos, como fazíamos sempre, pelas senhoras professoras da minha escola primária, hoje quase vazia. Nessa altura estava cheia de criancinhas de uma "baby boom generation" que hoje já deu os primeiros passos nos quarentas e nos cinquentas. Ainda não chamávamos "stôras" às professoras. Só no ensino secundário é que esse diminutivo apareceria. Nesse ano de 1974, fazia a minha quarta classe do ensino primário, penosamente, entre o conhecimento da produção de cacau do arquipélago de S. Tomé e Príncipe e o nome das localidades servidas pelo caminho de ferro de Benguela, de um pseudo-Portugal distante mas que, todavia, tínhamos a certeza existir, pois por vezes íamos a Lisboa chorar por 
simpatia com o povão sofredor, a partida de tios e primos para a guerra, nos navios do cais de Alcântara, apinhado de gente e de lágrimas. A sua chegada também. Sempre com lágrimas, que português é povo que chora muito.

Lembro-me, com se fosse hoje, que conhecíamos as professoras pelas cores dos elegantes sapatos que usavam, distintivos da sua posição social entre o povo boçal, no tecido rural deprimido situado à volta da escola. Então, esperávamos que chegasse a camioneta de carreira da Setubalense, riscada de verde e branco, com umas janelas traseiras arredondadas, enormes, em vidro amarelo transparente. Gostava de ir nesses lugares do fundo dessa camioneta quando ia a Salvaterra levar vacinas com a minha mãe. O meu aspecto, sempre doente, nesses dias de vacina, reforçava-se com o ar amarelado, com a que a luz coada por esse vidro colorido da janela iluminava a minha cara e a da minha mãe, sempre a dizer-me: "Não sejas mariquinhas!"; "Já és um homem!" para dar-me coragem até ao momento fatídico da espetadela. Aquele ferrão doloroso. Por cima do tejadilho, uma carga sempre generosa, com toda a espécie de mercadoria, presa com uma enorme rede de nylon. Estas camionetas ligavam a minha aldeia ao mundo e o mundo à minha aldeia. Nessa altura o mundo começava e acabava, a 45 km, em Vila Franca de Xira, início e fim de linha. Vila Franca era o mundo, a minha terra o fim dele ou...um outro mundo (dizem).

A minha professora da quarta classe, que se vestia quase como uma freira, mudou de visual desde que começara a namorar com o senhor de bigode da carinha dos livros (biblioteca itinerante da Gulbenkian). Hoje, acho que era o poeta Herberto Helder (ele chegou a trabalhar na Gulbenkian. Pois... o malandro!), tornara-se mais elegante, usava uns sapatos amarelos, ou brancos, em alternativa. Começara a sorrir e vimos-lhe, pela primeira vez, os dentes. E até nos dava menos reguadas nas mãos com aquela régua larga de madeira de pinho que era o terror da turma. Desprendeu o cabelo. Aparou o buço, mais ou menos proeminente, e até começou a usar baton vermelho-vivo nos lábios que só víamos às actrizes, projetadas em luz, no único cinema domingueiro da aldeia. Ainda que fosse uma rotina instalada desde há muito, esperávamos então que os passageiros descessem todos e, do outro lado da paragem, íamos confirmando as cores dos sapatos descidos, no campo visual retangular, por baixo da enorme massa metálica da camioneta da carreira. Nessa manhã de abril, desceram botins de borracha, sapatilhas de trapo, botas novas e botas velhas, sapatos de homem engraxados, e menos engraxados, pés descalços também. Mas sapatos de salto alto, de verniz e cores vivas, nem vê-los. As professoras faltaram todas. Faltaram todas!!!!! Um sumiço inesperado, mágico e maravilhoso. Depois da camioneta de passageiros ter prosseguido a sua 
marcha, rumo ao centro da aldeia, situada uns duzentos metros mais acima, após uma cautelosa confirmação visual, uma explosão de alegria atravessou espontaneamente a turba estudantil, ainda incrédula com o que tinha acontecido nessa manhã tão extraordinária de abril. Adivinhava-se um dia de correrias, jogo da bola, fisgadas nervosas e trogloditas nos pássaros do chaparral que, nessa altura, envolvia a escola. Sorrisos abriam-se de orelha a orelha. E até os pardais do chaparral pareciam piar mais alto por adivinharem o que Ihes iria "acontecer" nesse dia tão especial. Uma das funcionárias da escola, chegara-se muito aflita, e entre a chilreada já completamente incontrolada, teve de gritar bem alto: "HOJE NÃO HÁ ESCOLA, VEM AÍ A LIBERDADE!". As pessoas colavam os ouvidos nos rádios a pilhas e como não era dia de futebol, achei aquilo muito estranho. Nesse dia, depois das calorias gastas, fui para a minha casa da rua do Cabeço da Arroteia a pensar como seria a Liberdade? Que coisas maravilhosas teria para nos ensinar? Continuaria a humilhar os meus colegas com mais dificuldades, colocando-os com orelhas de burro, de cartolina amarela, à janela da sala para toda a aldeia passante ver? Seria capaz de nos ensinar a todos? Ela sozinha? Que histórias teria para nos contar? E a aritmética? Como ensinaria ela a odiada aritmética? Juntaria os meninos com as meninas? Como eu desejava isso. Deveria ser o máximo ter uma menina de trancinha e fita branca no cabelo sentada ao meu lado na carteira, a soletrar, afinadinha, o pretérito mais-que-perfeito do verbo namorar, numa comunhão perfeita. Mais importante ainda, de que cor seriam os seus sapatos? Os sapatos da Liberdade. Apostaria que seriam vermelhos. Era uma estranha premonição. Poucos dias depois, que nos pareceram semanas, fomos todos, muito curiosos, esperar a Liberdade, no local do costume. Uns soletravam "labardade", outros, "liburdade", outras ainda "lavardade". Quase todas soletravam, algo muito próximo a "verdade". Menos mal. No outro dia, um turbilhão inquieto de criancinhas, como um cardume de sardinhas, esperou ansiosamente, no outro lado da paragem, a camioneta da carreira da Setubalense. Essa mesmo, a do vidro traseiro amarelo. E ela lá apareceu roncando, listada horizontalmente de verde e branco, com o seu enorme lagarto pintado na chapa grossa. Precedido por um silêncio mais ou menos introspectivo, (e uma oraçãozinha maliciosa à Nossa Senhora da Glória: "Vá lá Santinha do Céu, dê-nos mais um feriadinho! Ou, se essa Liberdade vier, que seja boa pra agente!"). Lá nos inclinamos coletivamente, em reverência oriental, espreitando por baixo da camioneta da carreira, nessa coreografia rotineira. Desceram os botins de borracha, as sapatilhas de trapo, os sapatos, as botas, novas e velhas e...espanto nosso, em cadência de relógio de cuco, o par de sapatos de salto alto amarelos (os da minha professora!), os brancos, mais uns brancos, uns azuis, uns beges e uns pretos, outros pretos. Céus! Quando a camioneta seguiu marcha, perante os nossos olhos esbugalhados de espanto, as respectivas professoras estavam dentro deles!

Revista Digital do LAV - Santa Maria - vol. 11, n. 2, p. 135 - 146 - mai./ago. 2018 ISSN 1983 - 7348 http://dx.doi.org/10.5902/1983734833901 
Todas elas! Foi agora outra espécie de milagre, mas feito ao contrário. Passada a desilusão (talvez igual à de hoje) que uma Liberdade, mulher talvez bonita e providencial, como são as nossas mães, nos iria salvar, arrancando-nos das profundezas da ignorância, em lições doces, dadas entre sorrisos sábios e enternecedores. Nada disso aconteceu, retomamos às aulas rotineiras até o final do ano e até ao exame final da quarta classe. A minha ingenuidade infantil morrera ali. Mas tinha-me custado tanto como a "morte" do pai Natal, quando aos seis anos descobri que aquela bicicleta vermelha que recebi, cuidadosamente embrulhada com uma enorme fita azul, em papel brilhante, afinal, tinha sido comprada pelo meu pai. Chorei que me desalmei nesse dia de revelação trágica, às escondidas. Mas depois da revolução de 25 abril de 1974, que devolveu a democracia à Portugal, a parte melhor, é que deixamos de decorar as toneladas de produção de cacau e de sisal do arquipélago de S. Tomé e Príncipe, as estações do caminho de ferro de Benguela dessa Angola imensa, tão distante, e outras abstrações e idiotices para crianças de nove e dez anos. Muito em breve essas colônias iriam ser países. Quanto à liberdade, penso que ainda andamos todos atrás da sua configuração, da sua verdadeira forma. Ou, pelo menos, da sua aplicação efetiva e afetiva. E que ela nos foge sempre como um pequeno animal selvagem, assustado, à frente das novas tiranias das quais, diga-se em boa verdade, também não conhecemos lá muito bem o seu aspecto, para grande azar nosso e do futuro que queremos preparar para os nossos filhos.

\section{Fragmento 3: (Crescer e viver com) o nome impronunciável de minha mãe}

Há uma condição na nossa vida da qual nunca nos livramos: a de viver com o nosso nome e com o nome dos nossos progenitores para todo o sempre. Refiro-me aos três nomes pessoais que temos nos nossos documentos de identificação, como se um sistema cego que parece nos controlar, desconfiando se somos mesmo humanos, necessite que mostremos, sistematicamente, por quem fomos gerados. Essa prova vital do nome dos nossos pais. Nunca somos um, somos três. Às vezes muito mais, se olharmos mais para trás. Aconteceu na minha história familiar que o meu avô materno José Custódio quando foi registar a sua primeira e única filha (a segunda mais velha entre vários filhos, todos homens) não tinha dinheiro para pagar essa obrigação legal. E foi uma professora, ao que parece, refugiada judia, fugida da Alemanha em Guerra, quem se ofereceu para pagar esse custo que deveria ser significativo para um pobre assalariado rural, como o meu avô, nesses anos duros e cinzentões do salazarismo de má memória. A pobreza sempre foi a condição do meu avô para que aceitasse esse "negócio" aparentemente cheio de vantagens. A tal senhora, madrinha ocasional, apenas exigiu que fosse ela a pôr o primeiro nome ao bebê: "Nanzianzena" logo seguido de dois apelidos mais, digamos,

Revista Digital do LAV - Santa Maria - vol. 11, n. 2, p. 135 - 146 - mai./ago. 2018 ISSN 1983 - 7348 http://dx.doi.org/10.5902/1983734833901 
portugueses: "Quitéria" e "Verde". Menos mal. Por isso, essa memória de 1941, da segunda guerra mundial, dos milhares de judeus salvos das garras assassinas de Hitler com passaportes falsos, pelo cônsul português de Bordéus, Aristides da Sousa Mendes, passaram, indiretamente, a constituir parte das minhas memórias familiares. Ouvi contar aos mais velhos que o meu avô andou muito tempo com um papelinho embrulhado no bolso, com o nome escrito da filha que dava a ler às pessoas (que sabiam ler nessa altura, que deveriam ser bem poucas). Nem ele sabia muito bem ao certo soletrar tantos "zês" e tantos "enes". Quiçá, amaldiçoando a hora em que não pagou do seu bolso pelo registo de um nome mais amigável para criança: uma Jacinta como a mãe, uma Isabel como a avó... entre as opções femininas antepassadas. Com o tempo, o uso popular e comunitário da onomástica, essa "ciência dos nomes" logo reduziu o nome para o diminutivo "Nazia" e foi como o menino da Nazia que entrei no outono de 1970, minúsculo, loirinho, com uma bata branca, e os olhos bem abertos, na escola primária de Glória do Ribatejo. E após o a, e, i, o, u, o abecedário e os primeiros ensaios caligráficos identitários, descobri, com espanto, que não era filho da "Nazia" mas de uma "Nanzianzena" desconhecida que constava, para minha estranheza, na minha cédula de nascimento. E a muito custo, procurando não baralhar os quatro "enes" com os dois "zês" do nome, lá consegui, julgo que ainda antes do final do ano letivo, escrever o nome "oficial" da minha mãe. Na verdade, um "ene" não passa de um "zê" que deu uma meia volta na horizontal, batido pelo vento norte, ou por algum empurrão infantil liliputiano. Ou vice-versa. E isso baralha muito a cabeça de uma criança debutante nessa coisa difícil de escrever. No início, ainda ensaiei, num arrombo de criatividade (talvez mesmo a minha primeira experiência criativa) de escrever o nome fonético, separando, Nazia (comendo um " $n$ " como eu ouvia à vizinhança e próxima da realidade que encaixava com o rosto da minha mãe) seguido de Anzena (qualquer coisa parecido com farinha Maizena, que seria assim um apêndice dispensável). Nazia Anzena era a minha tentativa de atirar o barro à parede, a ver se pegava e resolvia uma parte das minhas dúvidas existenciais. Mas logo fui repreendido pela professora Teresa que, com as suas longas unhas vermelhas, a servir de apontador, bem por baixo da minha experiência caligráfica. "Não senhora meu menino! É tudo pegado. Não sejas preguiçoso"; "Não tenho culpa de terem dado este nome à tua mãe!". E tive que crescer com este sentimento de estranheza de não ver o nome oficial da minha mãe encaixar com o seu rosto, confirmado pelo nome mais curto e amigável com que o povo da minha aldeia a chamava. Pois é, por vezes crescer... dói muito. Acredito que no céu não precisamos de nomes. E a minha mãe, feita luz, lá cintila entre as estrelas, sem "enes" e "zês" a atrapalhar.

\section{Fragmento 4: Com pedras quentes na mão}




\section{De novo, a infância...sempre a infância}

Durante muitos anos meu pai foi funcionário de escritório de uma companhia de construção civil que tinha estaleiros e obras em muitas partes do país. Como viajava e mudava de casa frequentemente, por razões escolares, eu por vezes ficava com a minha avó materna ribatejana e a minha irmã mais velha ficava com a outra avó alentejana. Todos os meus outros irmãos e irmãs, mais novos, nesta altura, só ainda "existiam" molecularmente, infimamente, na graça omnipotente do Senhor lá do Céu. Chegaram todos ao mundo anos depois (1970, 1972, 1974, 1978). Bonitos, Graças a Deus, numa cadência regular mais ou menos bi-anual. Um negócio sábio estabelecido entre a minha santa mãe, o meu pai e o misterioso relógio cósmico que ninguém sabe como funciona. Para certos casais não dá horas, para outros dá horas a mais. Eu tinha iniciado o primeiro ciclo de ensino e a minha irmã Bela, mais velha que eu seis anos, tinha iniciado o ciclo de ensino seguinte, numa escola de Elvas, a cidade natal de meu pai, a cerca de $200 \mathrm{Km}$ onde eu vivia e onde ambos nascemos.

Nesses tempos só éramos conduzidos à escola por um adulto no primeiro dia de aulas, depois tínhamos que ir a pé, normalmente em grupo organizado espontaneamente em cada bairro, numa época em que tudo parecia ser mais amigável e mais seguro. Hoje, os alunos chegam de carro, como os ministros que vemos na TV, conduzidos principescamente por familiares de cabelo grisalho. Avô e avó servem para tudo.

Os meus avós maternos eram muito pobres, com alguns filhos solteiros e alguns filhos casados ainda vivendo com eles. Era incrível como toda aquela gente cabia naquela casa hoje arruinada e tão pequena. Alguns dos meus tios solteiros eram pouco mais velhos que eu, o que nos permitia ainda partilhar jogos e brincadeiras intermináveis. Lembrome dos curtos dias frios de inverno, da água do alguidar congelada lá fora e do bafo de vapor de água com que transformava em espaço vital, sob a minha respiração, a superfície no vidro da janela. Por vezes aí me entretinha a desenhar, com o dedo em riste, entre as pequeninas gotículas de água, o que me ia à alma. Usava essa tecnologia dedal verdadeiramente ecológica, para espanto de meus tios, admirados com minha precocidade artística. Lembro-me bem do que fazia: desenhava sistematicamente o Super-Homem, meu primeiro herói das revistas de quadrinhos que os meus tios que trabalhavam na construção civil, nos arredores de Lisboa, me traziam com regularidade. Sempre com os braços abertos, o corpo em V. Entrar na pele de uma personagem que voava, nessa altura, era quase uma obsessão. E quando chegava o fim de semana: "Avó, quero a minha roupa vermelha do Super-Homem!", depois do banho rotineiro coletivo tomado invariavelmente com sabão azul num enorme alguidar de zinco, colocado bem no 
meio da cozinha, esfregado pela multidão de mãos femininas da casa, com a água aquecida à lareira em grandes potes de barro.

Nesses invernos da minha infância, nunca irei me esquecer da forma como a minha avó me enviava para a escola depois de encher a barriga digerindo, quase todos os santos dias, uma fatia grossa de pão caseiro, untada com banha de porco e polvilhada com açúcar amarelo, às vezes com canela, mergulhada em água com café para amolecer a dureza de um pão que era feito para durar toda a semana. Como me sabia bem aquilo!

Minha avó aquecia, na lareira de chão, duas pedras redondas, em formato de ovo, daquelas que se podem apanhar com frequência nos leitos de ribeiros e riachos. $E$ antes de me ir, com a sacola azul dos meus livros e cadernos a tiracolo (onde tinha desenhado, claro, o Super-Homem) punha-me uma pedra quente em cada mão. E era assim, com duas pedras em cada mão, colocadas nos meus bolsos, que tomava a direção da escola. Era uma viagem de uns 15 minutos a pé, saltando poças e riachitos, dessas invernias inclementes, que corriam cabeço abaixo, na rua do "ti Tareso".

Penso ainda hoje na precisão com que minha avó, com a sua calma olímpica, controlava a temperatura das pedras, à medida que eu tomava essa refeição repetitiva, de pão amolecido em café, afastando regularmente, das brasas do fogo, essas pedrinhas que me permitiam chegar à escola com as minhas mãos quentes nesses invernos duros e ásperos da minha infância.

Esta sabedoria, de experiência feita, sempre me fascinou nas pessoas mais velhas. A temperatura dessas pedras foi sempre uma temperatura ideal, calculada impecavelmente para a minha pele infantil. Sabia descontar das suas mãos calejadas e ásperas, a finura da minha pele infantil no teste que fazia antes de as colocar nas minhas mãos. Formidável, avó.

\section{A escola}

A escola ainda hoje existe e a minha antiga sala de aula já foi frequentada pelas minhas duas filhas. Exatamente, essa sala do lado esquerdo do rés-do-chão. Sempre que lá ia falar com a professora, parecia-me que a sala encolhera, por obra de algum abraço mecânico gigante, achando-a extraordinariamente pequena para que tivesse albergado quase 40 crianças nesses inícios dos anos 70. Hoje tem apenas 17 alunos (acho!). No meu país as crianças são como alguns animais selvagens de África, estão em vias de extinção, e já não deve haver avós com sabedoria, sensibilidade e precisão para colocar 
pedras quentes nas suas mãos. E, em boa verdade, as suas mãos são hoje aquecidas por luvas de pele sintética Made in China, essa fábrica do mundo.

\section{Os amores}

A minha primeira namorada chamava-se Rosa e morava no outro lado do largo do Rato. O meu campo de batalha, o meu espaço vital. A Rosa, na sua fase de "Rosinha" era um encanto, e ao fim de semana eu vestia-me todo de vermelho (calça e camisola) só para me colocar vistoso para ela. Imaginava-me o Super-Homem que preenchia, tão obsessivamente, a minha vida, e uma vez quase levei um estalo da minha avó por querer sair de casa com uma toalha de banho aos ombros imaginando que assim, de capa, seria mais fiel à minha personagem.

\section{Por fim, a profissão}

Cheguei à minha profissão em 1988 quase por acaso (ou talvez não). Era aluno de Belas Artes na Universidade do Porto, o resultado lógico de tanto desenho compulsivo na infância, e precisava pagar os meus estudos que desbastavam violentamente o orçamento familiar. Em casa chegamos a ser seis estudantes em simultâneo. Passar das tintas de óleo Ferrario (mais baratas) para as Winsor \& Newton ou Le Franc \& Bourgeois (mais caros), era também uma mudança de estatuto na minha pintura. Comecei, portanto, a dar aulas ainda estudante de Belas Artes numa escola da periferia. E fui um trabalhador-estudante assíduo e dedicado nos dois lugares. Lá ia do Porto para Leça da Palmeira no autocarro número quarenta e quatro, com peixeiras, operários e gente de toda a espécie. Passando pelo porto de Leixões. Um senhor, adepto do Sporting, delirava com as derrotas (poucas) da equipa de futebol do Porto e, por vezes, com as do Benfica também. Conversa sempre igual, todos os dias. Tudo se foi tornando familiar com o passar do tempo. Uma grande família, ainda assim anônima, seguia naquele autocarro todos os dias, nas duas direções. Umas oitenta pessoas. Esta viagem suburbana também valia pela oportunidade de ver os magníficos reflexos de prata do atlântico, todos os dias, na curva larga antes da escola, no regresso à grande cidade. Um luxo para poucos. Ainda mais para um rural como eu, criado entre chaparros e estevas, e casarios brancos, desabituado da serena beleza do mar, ao final da tarde. Hoje não sei fazer mais nada, senão estar com pessoas e conversar com elas. Na verdade, eu não dou "verdadeiramente" aulas (é-me perigoso dizer isto!?) converso com as pessoas, e elas conversam comigo. Penso que aprendo sempre mais do que aquilo que ensino e faço aparentemente um bom negócio com quem me paga. E não me sinto desconfortável com esse sentimento. Às vezes gostaria de colocar umas pedras bem redondinhas e bem quentes nas mãos de cada aluno que quer ser professor e enviá-los para as escolas que um dia imaginaram. 


\section{(In) conclusões}

O filósofo espanhol Fernando Savater escreveu um dia que nós somos mais parecidos com contos do que com contas. E é verdade. Que a toda poderosa matemática nos perdoe, mais do que conjugações de números, nós somos o resultado de um largo somatório de contos que mais não são do que conjuntos de histórias reais que formaram e formam parte da nossa vida.

Utilizando a linguagem científica, essa mesma que evitei e a que andei sempre a fugir ao longo de todos os fragmentos do meu texto, posso dizer que a intensidade e a qualidade das experiências de aprendizagem que vivi nesse passado que circunscreveu a minha infância, é diretamente proporcional à dimensão vocacional da profissão que elegemos. Talvez devesse antes dizer que foi ela, a profissão, que me elegeu.

Não nascemos docentes mas muitos de nós, professores, já vivemos micro-docências informais em criança que nos marcaram mais do que imaginamos. Ensinava, frequentemente, os meus coleguinhas a desenhar e lembro-me de já usar, espontaneamente, linhas pré-esquemáticas para a figuração humana, essa temática sempre tão difícil de desenhar. Os meus talentos precoces a desenho na escola primária evitaram ser vitima de bullying (que nessa altura já existia, e de que maneira) e hoje já mereceu honras de nome científico e de grande preocupação das políticas educacionais contemporâneas. Eu era uma espécie de herói da escola e sentia-me maravilhosamente bem nesse papel com que atravessei todos os ciclos de ensino até ser diluído por talentos muito superiores ao meu na Faculdade de Belas Artes da Universidade do Porto.

Caricaturava os professores no ensino secundário, escudado, no fundo da sala, pelos meus colegas mais "volumosos" de corpo. E era sempre no fundo da sala que me sentava, para ter vista ampla, do tipo objetiva olho de peixe. E ninguém escapava ao meu lápis impiedoso. O professor de Filosofia, com os seus óculos de lentes "fundo de garrafa", acentuados com o devido exagero, o professor de Matemática com o seu sinal verruga protuberante na testa, ampliado em forma de vulcão, a professora de Português com a sua bunda descomunal, ampliada umas duas ou três vezes, para gaudio dos meus colegas admiradores.

Mal imaginaria eu que, anos depois, iria estar exatamente nesse mesmo papel e a ser sujeito (como já aconteceu) ao mesmo tipo de desenho caricatural com que os alunos talentosos no desenho se divertem a representar os professores. Os bons e os maus (que infelizmente também os há). Partidas do destino. Tenho-me esforçado por ser dos bons e por estar no lado correto da história.

Revista Digital do LAV - Santa Maria - vol. 11, n. 2, p. 135 - 146 - mai./ago. 2018 ISSN 1983 - 7348 http://dx.doi.org/10.5902/1983734833901 


\section{Nota única}

Texto escrito em memória da minha mãe Nanzianzena Quitéria Verde (1941-2011) e da minha avó Jacinta Quitéria ("Abrasques" de alcunha) (1917-2007) que, lá do Alto, deve estar com aquele seu sorriso peculiar, sempre misturado com aquela espécie de tosse... olhando-me, com aqueles olhos claros, lindos! E a minha mãe, finalmente a Nazia, a seu lado, muito espantada com o filho que gerou.

\footnotetext{
' Leonardo Charréu é licenciado em Belas Artes pela Universidade do Porto, mestre em História da Arte pela Universidade Nova de Lisboa, Doutor em Belas Artes pela Universidade de Barcelona e em Ciências da Educação pela Universidade de Évora. Lecionou na Universidade de Évora e na Universidade Federal de Santa Maria (UFSM), no Brasil. Foi professor visitante em várias universidades europeias e latino-americanas. Membro do CIED (Centro Interdisciplinar de Estudos Educacionais) do CIEBA (Centro de Estudos e Investigação em Belas Artes, FBAUL/UL) e do GEPAEC (Grupo de Estudo e Pesquisas em Arte, Educação e Cultura da UFSM. Pesquisa sobre Formação de Professores de Artes Visuais, sobre Arte e Cultura Visual, Arte e Cognição e Metodologias de Pesquisa baseadas nas Artes. Atualmente é professor na Escola Superior de Educação do Instituto Politécnico de Lisboa.
}

Como citar esse artigo:

Charréu, Leonardo. Infâncias, quadrinhos e ruralidade: Quatro fragmentos das histórias que vivi para me tornar no que sou. Revista Digital do LAV, Santa Maria: UFSM, v. 11, n. 2, p. 135-146, mai./ago. 2018. 